\title{
Control and Simulation of Static Condenser
}

\author{
K.R. Padiyar A. Lalsshmi Devi \\ Department of Electrical Engineering \\ Indian Institute of Science \\ Bangalore 560 012, India
}

\begin{abstract}
A static condenser is an advanced Static VAR Compensator (SVC) using voltage source converters with capacitor connected on the DC side. It has several advantages over both rotating synchronous condensers and variable impedance type SVCs and is expected to make a major breakthrough in the reactive power control in electric utility systems.
\end{abstract}

This paper presents the mathematical modelling and analysis of static condenser. The control parameters are based on eigenvalue analysis and the performance evaluated from digital simulation. The results from a case study show the benefits of static condenser in improving system stability and thereby increasing the power transfer in the line.

\section{INTRODUCTION}

Fast control of reactive power is an effective means of increasing power transfer in electric utility grid and variable impedance type Static VAR Compensators (SVC) using thyristor-switched capacitors (TSC) and thyristor controlled reactors (TCR) are already in use. With the availability of high power GTO thyristors, the reactive power control using switching converters and minimal energy storage elements becomes feasible [1-3]. If voltage source converters are used, this advanced type of SVC is called as STATic CONdenser (STATCON) [4].
STATCONs are considered to belong to the second generation of FACTS (Flexible AC Transmission System) controllers and expected to play a major role in the optimum and secure operation of $\mathrm{AC}$ transmission systems in future. [5-7].

The application of STATCONs would require a detailed analysis of the performance evaluation based on suitable models. Reference [8] has presented a simplified mathematical model of STATCON and derived transfer functions needed for control system synthesis. In [9], the use of a STATCON for system stabilization was demonstrated. This paper is aimed at presenting a mathematical model of STATCON using D-Q variables in a synchronously rotating reference frame which is more convenient to use than Park's reference frame. The design of the controller is based on eigenvalue analysis of the small signal model. The application of STATCON is illustrated from a case study of a single generator system. The benefits of a STATCON connected at the midpoint of a long $\mathrm{AC}$ transmission line are evaluated from digital simulation.

\section{DESCRIPTION OF A STATCON}

STATCON is a solid-state switching converter capable of generating or absorbing independently controllable real and reactive power at its output terminals, when it is fed from an energy source or an energy storage device of adequate capacity at its input terminals. 


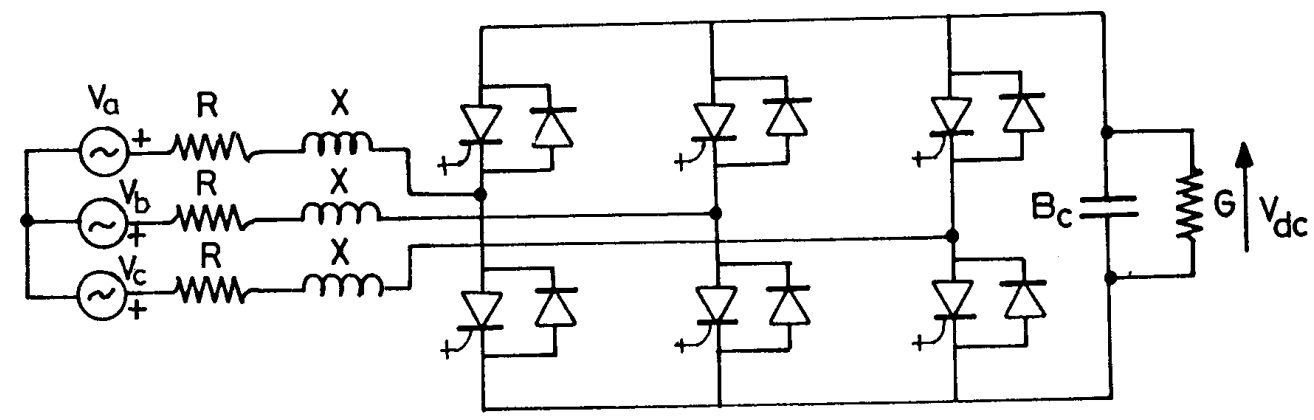

Fig. 1. An elementary STATCON

A basic STATCON scheme with an elementary six pulse Voltage Source Converter (VSC) is shown in Fig. 1. Here, a set of three phase AC output voltages are produced from the input DC voltage. By varying the magnitude of the output voltage (which is essentially in phase with the system voltage) of the STATCON, reactive power output can be controlled. The DC input voltage is provided by an energy storage capacitor.

The output voltages contain harmonics. By combining a number of six pulse VSCs into a multi-pulse configuration, the voltage distortion can be reduced. Reference [9] describes a 80 MVA, 48 pulse system using 8 GTO based inverters.

\section{MATHEMATICAL MODEL}

Consider a STATCON using a six pulse voltage source converter (VSC) shown in Fig. 1. (Although a six pulse converter is considered for simplicity, the analysis can also include multipulse converters). $\mathrm{R}$ and $\mathrm{X}$ represent the leakage impedance of the transformer through which STATCON is connected to the system. G and $B_{c}$ are the conductance and susceptance of the capacitor connected at the DC terminals. $v_{a}, v_{b}$ and $v_{c}$ are the $\mathrm{AC}$ supply voltages.

Neglecting harmonics and using $D-Q$ variables on the $\mathrm{AC}$ side, the equivalent circuit is shown in Fig. 2. The equations for the system of Fig. 1 $\stackrel{\text { are }}{\omega_{b}} p i_{D}+X i_{Q}+R i_{D}=e_{D}-v_{D}$
$\frac{X}{\omega_{b}} p i_{Q}-X i_{D}+R i_{Q}=e_{Q}-v_{Q}$
$\frac{B_{c}}{\omega_{b}} p v_{d c}+G v_{d c}=-i_{d c}$
$e_{D}=k v_{d c} \sin \alpha, e_{Q}=k v_{d c} \cos \alpha$
$i_{d c}=k\left[i_{D} \sin \alpha+i_{Q} \cos \alpha\right]$

where $p=\frac{d}{d t}, \omega_{b}=2 \pi f_{b}, f_{b}=$ nominal frequency and $\mathrm{k}$ is a constant

The steady state operating values of $v_{d c}, i_{D}$ and $i_{Q}$ as functions of the control angle $\alpha$ for typical parameter values and 1 pu supply voltage, are shown in Fig. 3. Here, $v_{D}$ is assumed to be zero $\left(v_{Q}=1.0\right)$ and $i_{D}$ is the reactive component of the STATCON current.



Fig. 2. Equivalent circuit 


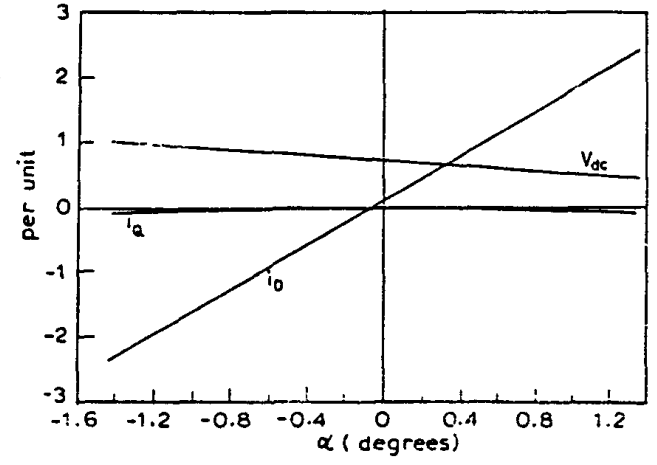

Fig. 3. Steady state characteristics

The negative values of $i_{D}$ correspond to positive reactive power injection from STATCON (appearing capacitive). Fig. 3 shows that the reactive current can be varied over a wide range by small variation in $\alpha$. There is a slight reduction in $v_{d c}$ as STATCON changes from capacitive to inductive region. $i_{Q}$ is the active current component to meet the power losses.

\section{CONTROL OF STATCON}

If STATCON is used for the voltage control in transmission networks, the block diagram of a controller (based on the control of conventional SVC) is shown in Fig. 4. $k_{D}$ is the slope of the steady state control characteristic shown in Fig.5 $T_{m}$ and $T_{s}$ are time constants representing measurement and converter control delays.

Combining the controller equations with those of STATCON (1-5), the overall system model is obtained. The equations can be linearized about an operating point and can be expressed as

$$
\dot{x}=[A] x
$$

where $\mathrm{A}$ is a $6 \times 6$ matrix. $x$ is a state vector of small deviations about the steady state values.

Eigenvalue analysis is used to select the control parameters. For example, with $K_{2}=-50$, the locus of a complex critical eigenvalue with variation in $K_{1}$ (from 0 to -12.0 ) is shown in Fig. 6. From the root locus, the optimum value of $K_{1}$ is chosen as -1.8 . The eigenvalues of the system for $K_{1}=-1.8$, and $K_{2}=-50$ are given below

$$
\begin{aligned}
& s_{1}, s_{2}=-12.7 \pm \mathrm{j} 1074.0 \\
& s_{3}, s_{4}=-62.4 \pm \mathrm{j} 113.0 \\
& s_{5}=-481.4 \\
& s_{6}=-30.3
\end{aligned}
$$

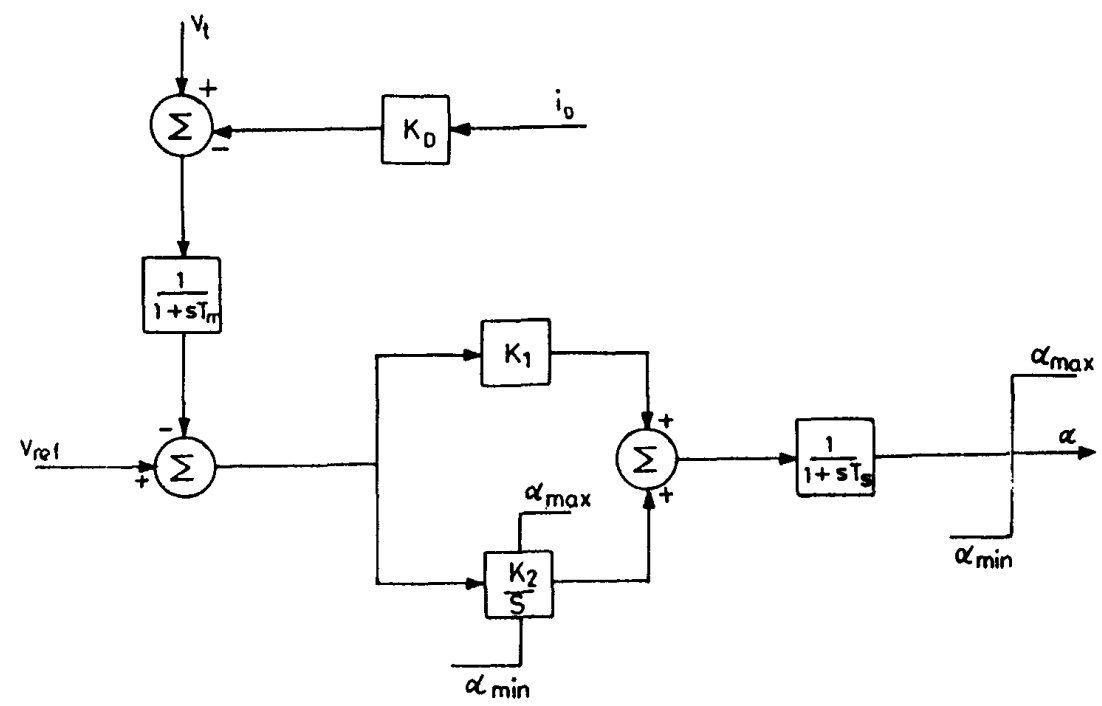

Fig. 4. Block diagram of controller 




Fig. 5. Steady state control characteristics

The second complex pair $\left(s_{3}, s_{4}\right)$ and the real eigenvalue $s_{5}$ result from the controller dynamics.

\section{V.APPLICATION OF STATCON - A CASE STUDY}

The STATCON is connected at the midpoint of a double circuit transmission line carrying power from a single synchronous generator to a load centre (represented as an infinite bus). The single line diagram of the system considered is shown in Fig. 7. The generator is modelled in detail. The synchronous machine is represented by two-axis model including the field winding on the d-axis and a damper winding on the $\mathrm{q}$-axis. The excitation system is represented by a single time constant model (corresponding to a static exciter). Power System Stabilizer (PSS) for damping rotor oscillations (to counter the negative damping introduced by the high gain Automatic Voltage Regulator (AVR)) is also included.

The system data is taken from [10]. The system consists of a $1100 \mathrm{MVA}, 50 \mathrm{~Hz}$ generator supplying power over a $600 \mathrm{Km}$ long transmission line rated at $400 \mathrm{kv}$. The STATCON is rated at \pm 300 MVAR. The generator is initially operating at an output of $800 \mathrm{MW}$ when it is subjected to a large disturbance in the form of a three phase

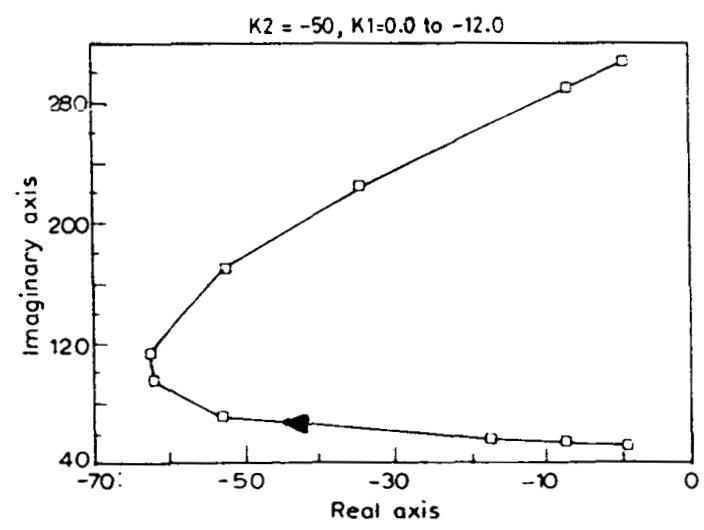

Fig. 6. Eigenvalue locus

fault at the generator terminals, followed by clearing of the fault after 4 cycles.

The AC network is modelled by algebraic equations (neglecting the transients). The nonlinear differential equations of the generator and STATCON are solved numerically along with the linear algebraic equations of the network. The results of the digital simulation are used to evaluate the performance of STATCON when subjected to large disturbances. The variation in the generator rotor angle $\delta$ (referred to a synchronously rotating reference frame) is shown in Fig. 8. The two cases a)without STATCON and b) with STATCON are compared.

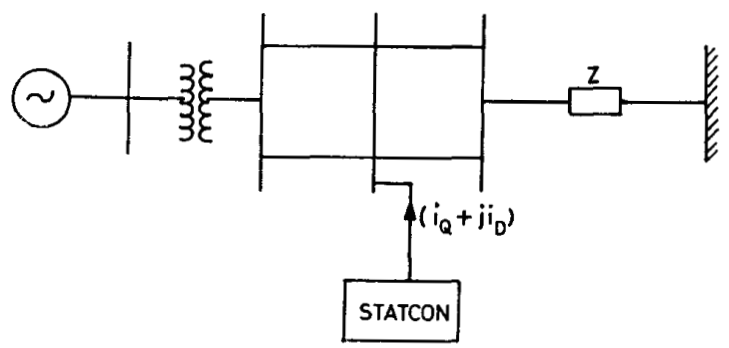

Fig. 7 . One line diagram of the single generator system 


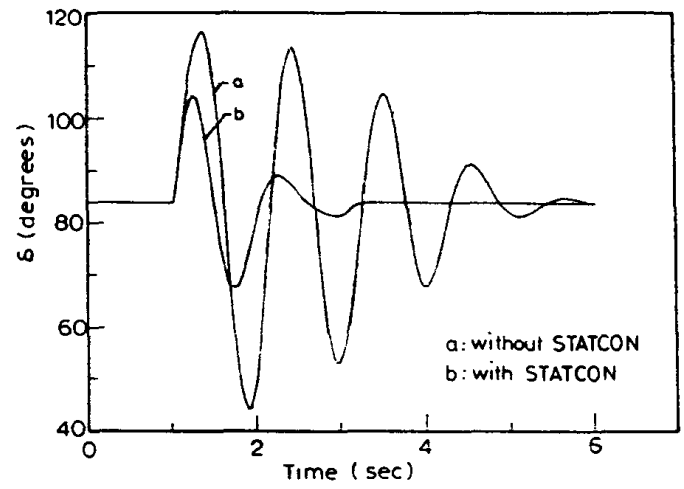

Fig. 8. Variation of rotor angle

The benefits of STATCON in reducing the peak overshoot and damping of the rotor oscillations are obvious. This shows that both transient and dynamic stability of a power system are improved by a suitably controlled STATCON.

Although not shown here, the results were also obtained for other disturbances such as a) step change in the mechanical torque and b)fault at the SVC bus. In all cases, the effect of STATCON

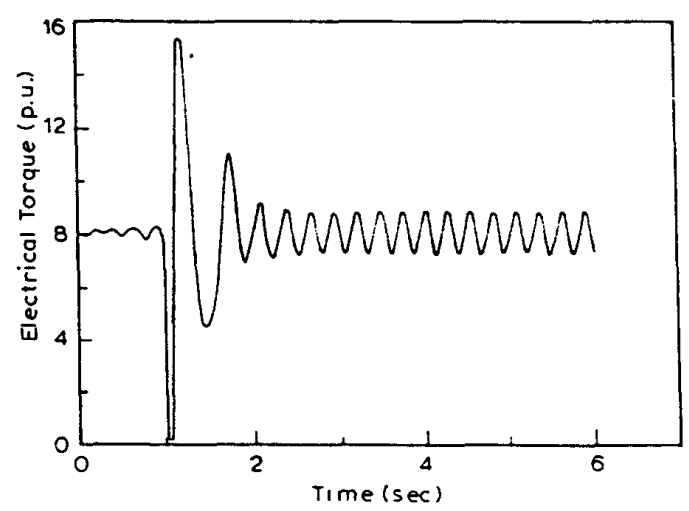

Fig. 9. Variation of electrical torque was to increase the speed of response and damp oscillations.

In comparison with variable impedance type SVC, STATCON has better control characteristics. For example, when operating at the limit, the SVC current will vary in proportion to the voltage. However, STATCON can generate a capacitive current independent of the voltage (except when it is too low). Also, the current can exceed the steady state rating during a transient. While these advantages are beneficial in the application of STATCON, it is essential to ensure that the control system of STATCON works reliably. The failure of TCR or TSC control will not result in instability. But failure of STATCON control can result in instability. The variation of the electrical torque for failure of control is shown in Fig. 9. This shows sustained torque oscillations. This is to be compared with the results in Fig. 10 for a)without STATCON and b)with STATCON (with controls functioning normally). The disturbance considered is the same as considered earlier, a fault at the generator terminals followed by clearing.



Fig. 10. Variation of electrical torque 


\section{CONCLUSIONS}

The analysis and simulation of a STATCON for reactive power control are presented in this paper. The equations of STATCON are obtained using $D-Q$ variables on a synchronously rotating reference frame. The controller parameters are determined from eigenvalue analysis using small signal model. The results from a case study show the benefits of STATCON in improving transient stability and damping oscillations. However, it is necessary to ensure that STATCON controls work reliably during a disturbance. With the present state of technology in digital control,this is not difficult to achieve.

\section{REFERENCES}

1. L.Gyugyi, 'Reactive power generation and control by thyristor circuits', IEEE Trans., vol IA-15, No.5, pp.521-532,Sept/Oct 1979.

2. L. Gyugyi,' Power Electronics in electric utilities, Static Var Compensators', IEEE Proc., vol. 76, No. 4, pp. 483-494,April 1988.

3. C.W. Edwards,K.E. Mathew,E.J. Stacey, P.R. Nannery and J.Gubernick, 'Advanced Static VAR Generator employing GTO thyristors', IEEE Trans., on Power Delivery, Vol. 3, No.4, pp. 1622-1627, October 1988.

4. H. Mehta,T.W. Cease, L.Gyugyi and C.D. Schauder, 'Static Condenser for Flexible AC Transmission Systems', Paper presented at FACTS EPRI Workshop, Boston, May 1992

5. N.G. Hingorani, 'FACTS - Flexible AC Transmission System', Conf. Publication No. 345, IEE Fifth Int. Conf. on AC and DC Power Transmission, London, pp.17,Sept. 1991.

6. J. Douglas,'FACTS - Delivery system of the future', EPRI Journal, pp.5-11, Oct/Nov. 1992
7. E.Larsen, N. Miller, S.Nilsson, S.Landgran, 'Benefits of GTO-based compensation systems for electric utility applications', IEEE Trans. on Power Delivery, vol.7, No.4, pp.2056-2064, Oct. 1992

8. C.D. Schauder and H. Mehta, 'Vector analysis and control of advanced Static Var compensators', Conf. Publication. No. 345,IEE Fifth Int. Conf. on 'AC and DC Power Transmission', pp. 266-272,1991

9. S. Mori et al, 'Development of a large static VAR generator using self-commutated inverters for improving power system stability', IEEE Trans. on Power Systems, vol. 8, No.1, pp.371-377, Feb. 1993

10. K.R. Padiyar and R.K. Verma, 'Damping torque analysis of static VAR system controllers', IEEE Trans. on Power Systems,vol.6, No.2,pp.458-465, 1992 